\title{
Corrigendum: Female Genital Mutilation in Rural Regions of Iraqi Kurdistan: A Cross-Sectional Study
}

Public Health Reports

2019, Vol. 134(5) 577

(c) 2019, Association of Schools and

Programs of Public Health

All rights reserved.

Article reuse guidelines:

sagepub.com/journals-permissions

DOI: $10.1177 / 0033354919872146$

journals.sagepub.com/home/phr

@SAGE

Abdullah DM, Sedo BA, Dawson A. Female genital mutilation in rural regions of Iraqi Kurdistan: a cross-sectional study. Public Health Rep. 2019;134(5):514-521. doi:10.1177/0033354919860512

There were errors in the original abstract of the paper. The abstract has now been corrected online and in print. 